\title{
Е.Ю. Куликова
}

Новосибирский государственный педагогический университет

\section{Мотивы плавания и кораблей в очерке В. Ходасевича «Бельфаст»}

Аннотация: Статья посвящена «путешествию» В. Ходасевича по верфям Бельфаста, описанному в одноименном очерке. Ходасевич осмысляет увиденное в контексте поэтической традиции, отсылая читателя, прежде всего, к «Божественной комедии» Данте. В статье рассматривается, как эсхатологические образы гибнущих кораблей (знаменитый «Титаник» построен на верфи «Бельфаста») сочетаются в очерке с мотивами творчества, связанными для Ходасевича с пушкинской «Осенью», «Путешествием» и «Приглашением к путешествию» Бодлера.

The paper analyzes the essay where Khodasevich's describes a "journey" through the shipyards of Belfast. Khodasevich conceptualizes his observations in the context of the poetic tradition by referring the reader, predominantly, to Dante's "Divine Comedy". The paper discusses the ways in which the essay juxtaposes the eschatological images of dying ships (the famous Titanic was built in a Belfast shipyard) with the motifs of creativity which Khodasevich associated with Pushkin's "Autumn" and Baudelaire's "Voyage" and "Invitation to a Voyage".

Ключевые слова: жанр путешествия, интертекст, мотив, традиция, очерковая проза.

The voyage genre, intertext, motif, tradition, essay prose.

УДК: $821.0+821.161 .1$

Контактная информация: Новосибирск, ул. Вилюйская, 28. НГПУ, Тел. (383) 2680188. E-mail: kuliksa@rambler.ru.

Очерк В. Ходасевича «Бельфаст» был создан по впечатлениям августа и сентября 1924 г., времени, которое поэт прожил в столице Северной Ирландии. Очерк условно распадается на две части, первая из которых посвящена описанию самого города и его жителей, вторая - верфи. «Если к Бельфасту спускаться с высоких холмов... с северо-запада, - то столица Северной Ирландии покажется вам горстью земляники на кленовом листе: таковы, среди зеленых лугов, черепитчатые бельфастские крыши» [Ходасевич, 1997, с. 40 - далее страницы этого издаия приводятся в круглых скобках]. Так начинается очерк, и для первой его части (занимающей меньше половины) это самое поэтическое описание, потому что дальше Ходасевич будет подробно описывать «черную тучу дыма и копоти» над крышами, постоянно идущие дожди («с утра до ночи и с ночи до утра», 40), улицы и здания, «лишенные всякой прелести» (40), «так убийственно незанятные, что незанятно о них рассказывать... о них хочется сказать: помещения» (41), «серолицые, впалощекие, с перекошенными челюстями мужчины... и серолицые, впалощекие, с перекошенными челюстями, с огромными ногами, обутыми в непромокаемые штиблеты без каблуков женщины» (40).

Вторая часть очерка начинается со слов, явно поворачивающих читателя в противоположную сторону - от «скуки, бездарности и некрасивости»: «Однако же есть и в Бельфасте такое, на что взглянуть стоит... Это его гигантская верфь, 
вторая в мире по величине, выпускающая суда, по величине первые в мире» (42). Путешествие на верфь оказывается не обычным, а почти дантовским: герой получает своего проводника (он шутливо называет его «Виргилием»), за которым следует по кругам - сначала конторы («по бесконечным закругляющимся коридорам»), потом чертежных со стеклянными потолками, вписанных «внутрь кругов конторских», потом - по зигзагам «Виргилий» везет героя на машине на территорию верфи (513).

Верфь - это особый город, похожий на «самостоятельную республику... в нем свои улицы, рельсы, по которым ползут поезда вагонов и вагонеток» (43). В самом Бельфасте Ходасевич видит только унылое однообразие, а на верфи отмечает «разнообразие строений: кирпичные, каменные, деревянные, приземистые и низкие, то лишенные окон, то вовсе как бы стеклянные» (43). Здесь «все пестро, причудливо высятся разноликие здания, разнофасонные, высокие, низкие, толстые, тонкие трубы... Толпы каких-то башен и вышек, то каменных, то железных, то сплошных, то сквозных, точно сплетенных из проволоки... Подъемные краны, лебедки, мосты... А где-то вдали - гигантские кубы лесов, окружающих строящиеся корабли» (44).

Описание верфи у Ходасевича напоминает описание города - с оригинальной архитектурой, с выбивающимися из правильного ряда домами. У зданий на верфи, в отличие от жителей Бельфаста, разнообразные лица, разнообразные фигуры (разноликие, разнофасонные), «пестрые одежды», башни и вышки представляют собой интересный городской ансамбль из камня, железа и проволоки. И гигантские кубы лесов на фоне городского пейзажа напоминают геометрические картины кубистов.

«Металлический звон и жужжание» внутри строящихся кораблей приводят «путешественников» в краснодеревную мастерскую - «гигантский зал без единой перегородки», наполненный «бесчисленными станками, сверлами, пилами и лобзиками» (44). Затем следует мастерская, где изготовляют металлическую обшивку судов, и другая, где делают спасательные лодки. Первая рождает ассоциации с металлическими чудовищами с короткими хоботками и «железными черепахами, бегающими по железным мостам, вниз спиною, как мухи по потолку» (45), вторую пронизывает запах пахучих досок. Металлическое (неживое по определению) наделяется признаками жизни, сравнивается с копошением насекомых. И множество лодок - «готовых, полуготовых, только начатых, лежащих на боку, на спине, килем вверх» (45) - живут своей жизнью, той, в которую вовлечены рабочие, «стучащие, стругающие, шпаклюющие в них, на них, под ними» (45).

Поражает контраст в подмеченной Ходасевичем каждой детали на верфи и отсутствием этой «наполненности» в Бельфасте - никакие улицы, невыразительные строения, неинтересные жители. Между тем на верфи кипит живая жизнь, и это можно увидеть в каждом созданном образе. Ходасевич описывает увиденное так весело, используя многоуровневые ряды перечислений (без них невозможно себе представить это пространство), что бытие верфи брызжет через край и превращается из прозаического в поэтическое.

Но путешествие с Виргилием имеет свою цель, помимо осмотра общего вида и мастерских. Эта цель - корабли. Сначала в центр повествования вводятся два «левый» и «правый». «Левый почти готов к спуску. Это гигантская железная лодка, лежащая на деревянных подпорках и окруженная деревянными и железными лесами» (45). Вертикаль, заданная с самого начала описания верфи (лес труб, башни, вышки, кубы лесов, вверху железные черепахи на железных мостах), очерчивается еще эффектнее: «Где-то высоко, на высоте четырехэтажного дома, висящий в люльке рабочий стучит молотком» (45). По контрасту с высотой лесов, герой попадает «под днище, в темный коридор» (45). Повествователь оказывается внизу под кораблем, а вдали видит «маленькое светло-серое пятно, испускающее 
мутные лучи. Это - конец корабля и море» (45). Мир приобретает, помимо заданной вертикали, отчетливую горизонталь.

Очерк Ходасевича строится как сложная геометрическая картина, написанная любителем кубических форм: круги, зигзаги, кубы, прямоугольники, конусы, заполняющие пространство. Не случайно В.Б. Микушевич говорил о стихотворении Ходасевича «Перешагни, перескачи...», что оно написано современником «Черного квадрата». А С.Г. Бочаров формирует целостный образ поэта по стихотворению «Вдруг из-за туч озолотило...» («на листе широком / Отображаюсь... нет, не я: / Лишь узловатая кривая, / минутный профиль тех высот, / Где, восходя и ниспадая, / Мой дух страдает и живет»): «на месте его (Ходасевича - E.K.) оказывается геометрическая кривая, чертеж, диаграмма... Геометрический “профиль”, графическая черта, кривая, притом угловатая, на месте “я”, на месте лица поэта» [Бочаров, 2007, c. 414] ${ }^{1}$.

«Правый» корабль - еще остов, «не обшитый, с обнаженными гнутыми ребрами» (45). Строительство этого корабля происходит скрыто, где-то в глубине: «рабочих не вижу вовсе. Они копошатся где-то во вскрытом чреве гиганта, в том мраке, откуда, точно иллюминация, видны желтые пятна электрических лампочек. Всюду, похожие на кишки этого чрева или на лианы в лесу, - змеятся и тянутся провода, кабели, какие-то трубки... Весь корабль поет и звенит от бесчисленных электрических сверл. Это звук совершенно особенный, словами неизобразимый, пронзительный и - обаятельный» (45).

Образ строящегося корабля, созданный Ходасевичем, двойственный. В нем есть радость и поэзия, которые в то же время накладываются на жутковатую картину «вскрытого чрева» со змеящимися лианами или кишками внутри со световыми пятнами электрических лампочек.

В описании корабля есть косвенные переклички с картинами Дантова «Ада». Обозначим эти пересечения, быть может, не заостренные Ходасевичем специально, но, тем не менее, существенные, поскольку в пути по верфи героя сопровождает именно «Виргилий», и «Божественная комедия», так или иначе, становится скрытым фоном очерка.

Вскрытое чрево гиганта, мрак, «откуда, точно иллюминация, видны желтые пятна электрических лампочек» (45), напоминают строки из 26 песни «Ада»:

Tal si move ciascuna per la gola del fosso, ché nessuna mostra'l furto, e ogne fiamma un peccatore invola. [Dante]

(Так движется каждый через зев рва, который никому не показывает кражу, и каждое пламя похищает грешника)

В пер. М. Лозинского:

Так движутся огни в гортани рва

И в каждом замкнут грешник утаенный,

Хоть взор не замечает воровства

[Данте, 1992, с. 131] (курсив здесь и далее мой. - E.K.).

Змеящиеся провода, кабели и трубки непрямо отсылают к строкам из 24 песни «Ада»:

1 Знаменитый портрет В. Ходасевича кисти П. Анненкова отражает «геометрическую» сущность поэта, заостряет графичность его черт, их угловатость и «кубизм». 
E vidivi entro terribile stipa

di serpenti...

[Dante].

(И увидел там ужасную набитость змей).

В пер. М. Лозинского:

И я внутри увидел страшный ком

Змей...

[Данте, 1992, с. 122].

Bce, происходящее внутри корабля, скрыто от глаз, зато слух пронзает звук: «...если работники здесь незримы - они хорошо слышны. Весь корабль поет и звенит от бесчисленных электрических сверл. Это звук совершенно особенный... Он куда-то зовет - и разом вдруг обрывается на нестерпимо волнующем стоне» (45), пишет Ходасевич. Во «втором поясе» Ада читаем:

Io sentia d'ogne parte trarre guai e non vedea persona che 'l facesse; per ch'io tutto smarrito m'arrestai [Dante].

(Я сльшиал каждой стороной извлекаемую муку

И не видел лицо, которому она принадлежала,

Чтобы я, совершенно потерянный, мог остановиться)

В пер. М. Лозинского:

Я отовсюду слышал громкий стон,

Но никого окрест не появлялось

[Данте, 1992, с. 66].

Ходасевич воспроизводит эффект незримости множества людей по контрасту с особенным звучанием их действий. Само описание воспринимается иначе, чем в поэме Данта, но характерно, что почти веселый, «обаятельный» звук сверл в конце превращается в стон.

Кроме того, можно отметить еще одну ассоциативную линию - со скандально известным стихотворением Ш. Бодлера «Падаль». Кишение «во вскрытом чреве гиганта» (45) в очерке Ходасевича напоминает строки Бодлера, посвященные процессу разложения.

У Ходасевича:

Они копошатся где-то во вскрытом чреве гиганта, в ... мраке.

Всюду, похожие на кишки этого чрева или на лианы в лесу, - змеятся... провода, кабели... трубки...

Весь корабль поет и звенит от бесчисленных электрических сверл (45).
У Бодлера:

Les mouches bourdonnaient sur ce ventre putride,

D'où sortaient de noirs bataillons

De larve... [Baudelaire, p. 128]

(Мухи жужжсали на этом гнилом чреве,

Откуда выползали черные батальоны червей)

Жужжала стая мух над этим чревом темным,

Откуда...

Личины червяков ползли [Бодлер, 2001, c. 314]

$$
\text { - пер. Г. Адамовича }
$$


Это звук совериенно особенный, словами неизобразимый... Молотки, бьющие по железу, служат для сверл музыкальнылм фоном. Здесь, под открытым небом, их звук негромок и отрывист (45).
Et ce monde rendait une étrange musique...

[Baudelaire, p. 128]

(И этот мир издавал странную музыку)

И этот мир струил таинственные звуки [Бодлер, 2001, с. 317]

В описании Бодлера есть строки, в которых процесс разложения сравнивается с движением волны, что, собственно, является некоторым подтверждением нашей версии по поводу близости двух текстов. Готовый корабль в очерке еще не качается на волнах, он только строится, но мысль о его будущем движении явно волнует Ходасевича. Звук, который он слышит, наполнен будущим плаванием. Бодлер же из самой непоэтической картины создает абсолютно поэтическую:

Tout cela descendait, montait comme une vague, Ou s'élançait en pétillant;

On eût dit que le corps, enflé d'un souffle vague,

Vivant en se multipliant

[Baudelaire, p. 128].

(Все это опускалось, вздымалось, как волна,

Или, кипя, бросалось вперед,

Казалось, что тело, вздутое дыханием волны,

Оживало и множилось (увеличивалось))

В пер. Г. Адамовича:

Все это двигалось, вздымалось, опускалось,

Иль тучею неслось вокруг,

И тело мертвое, размножившись, казалось,

Как будто оживало вдруг

[Бодлер, 2001, с. 314].

Подобная отсылка к «Падали» Бодлера в очерке Ходасевича кажется поначалу несколько странной. Ведь описывается не разложение, а, напротив, процесс созидания! Тут всплывают образы «Петра в Саардаме и Робинзона за постройкою корабля» (45). Откуда же этот скрытый трагизм, «юродивый контрапункт поэтики Ходасевича» [Бочаров, 2007, с. 412]?

Ответом может служить финал очерка, в котором появляется третий корабль, находящийся на другом берегу мыса, занятого верфью. Он спущен и стоит возле берега. «Так как на нем еще нет ни кают, ни палуб, ни труб, ни мачт - одна лодка, - то здесь, на просторе, он не кажется... огромным. Однако это не так. Это самый большой корабль в мире из построенных после войны» (46). Виргилий объясняет, что корабль всего на семьдесят метров короче «Титаника». И в этот последний - момент, когда перед читателем едва начинает очерчиваться поэтическое будущее - и корабля, и героя-путешественника, и самого сюжета, наступает развязка: третий корабль не будет достроен и никогда не отправится в плавание. «Голландско-американская компания, заказавшая его, - предпочла потерять огромный задаток, нежели достраивать судно» (46).

Сравнение с «Титаником» обретает новый смысл: еще не построенный корабль оказывается погибшим. Упоминание о «Титанике» отзывается болью уже в чертежных, где герои рассматривают развешанные по стенам «рисунки и чертежи, относящиеся к судам... выпущенным верфью» (43). Во множестве висят 
«профили и горизонтальные разрезы “Мажестика”, эскизы панно для гостиных на “Олимпике”... все эти гигантские “ики”... построены здесь. Но - ни моделей, ни эскизов для покойного “Титаника” здесь нет» (43).

В финале катастрофичность сюжета складывается из разных, разбросанных по всему тексту эпизодов, мотивов, неявных линий и очертаний. Вечный дождь в Бельфасте обыгрывает одну из картин дантовского «Ада» (В начале очерка: «Я пробыл поблизости от Бельфаста шестьдесят летних дней; из них два обошлись вовсе без дождя, дней десять шел дождь с перерывами, а прочие сорок восемь суток он лил себе с утра до ночи и с ночи до утра» (40). В последнем абзаце: «Дождь, дождь, дождь» (46)):

Io sono al terzo cerchio, de la piova etterna,

maladetta, fredda e greve;

regola e qualità mai non l'è nova.

Grandine grossa, acqua tinta e neve

per l'aere tenebroso si riversa;

pute la terra che questo riceve [Dante].

(Я в третьем круге, где дождь вечный (нескончаемый),

проклятый, холоднылй и тяжёльй;

порядок и свойство никогда не новы.

Крупный град, пятнистая вода и снег

в воздухе мрачном кидается;

смрад издает земля, которая это вмещает)

В переводе М. Лозинского:

Я в третьем круге, там, где дождь струится,

Проклятый, вечный, грузный, ледяной;

Всегда такой же, он все так же длится.

Тяжелый град, и снег, и мокрый гной

Пронизывают воздух непроглядный;

Земля смердит под жидкой пеленой

[Данте, 1992, с. 32].

Мотивы, связанные с «Титаником», поддерживают эту эсхатологию. Добавим, кроме того, что для Ходасевича, как и для Пушкина, морские и корабельные мотивы непосредственно связаны с мотивами творчества. Поэт, сидящий с пером в руке, сродни моряку, покоряющему неведомые пространства. Не случайно «Осень» Пушкина, где одно время года сменяет другое, чтобы вылиться в осень пору созидания («Теперь моя пора»), завершается «приглашением к путешествию». В IX строфе параллельно с описанием творческого процесса вводится образ корабля, отправляющегося в плавание.

Поэтический контекст этого мотива - «Le voyage» Бодлера, название которого М. Цветаева перевела как «Плаванье», а не «Путешествие», его же «L'invitation au voyage» («Приглашение к путешествию»), «Сентиментальное путешествие» Гумилева и его «Приглашение в путешествие», название которого звучит, безусловно, как цитата из Бодлера. Для Ходасевича особенно значимой была, конечно, перекличка с пушкинской «Осенью».

И вот «Куда ж нам плыть?» остается без ответа. Это 1925 год, год-рубеж, после которого Ходасевич почти перестанет писать стихи. Будут в 1926 и 1927 гг. несколько стихотворений - очень трагических - «Бедные рифмы», «Сквозь нена- 
стный зимний денек...», баллада «Джон Боттом», недописанные отрывки, в 1928 г. - «Памятник», а в 1934 - «В последний раз зову Тебя...» (Тебя - это Музу, «явись на пиршество ночного вдохновенья»), печально-светлые, абсолютно гармоничные строки стихотворения «Памяти кота Мурра» и последний поэтический текст - знаменитое «Не ямбом ли четырехстопным...» (1938), необычно радостное и счастливое для Ходасевича вообще. Но сборников стихов больше не появится, останутся - проза, критика, журналистика. Недостроенный корабль будет только качаться в волнах возле берега.

Личная судьба поэта, так или иначе, будет спроецирована судьбу его страны, на потерю, которую понесли эмигранты, оставив Россию, и на потерю, которую понесла Россия. В этом контексте всплывает еще одна ассоциация из очерка «Бельфаст». Когда, подобно Данту и Вергилию в «Божественной комедии», герои «между подпорками пролезут под днище, в темный коридор» (45) уже готового к спуску достроенного, «благополучного» корабля (у Данте: «Спустились в крутоскатый / И дырами сияющий провал» ${ }^{1}$ (пер. М. Лозинского) [Данте, 1992, с. 96]), Ходасевич напишет: «Корабль висит у меня над головой» (45). Этот висящий в воздухе корабль напоминает воздушный корабль Лермонтова. Одинокий корабль-фантом Лермонтова возвращает на родину фантома - Наполеона, восстающего для этого путешествия из гроба. Этот путь видится Лермонтовым как путь поэтический. Так и воспринимала это стихотворение русская эмиграция. Во всяком случае, Г. Адамович, литературный противник Ходасевича, написал стихотворение «Когда успокоится город...», впрямую ориентированное на «Воздушный корабль» ${ }^{2}$.

В очерке Ходасевича нет признаков тоски по России, напротив, в характерной для него манере он иронизирует над русскими поэтами, пишущими стихи о

\footnotetext{
${ }^{1}$ Seguendo lui, portava la mia fronte come colui che l'ha di pensier carca, che fa di sé un mezzo arco di ponte... [Dante].

(Я следовал за ним, он вел меня, Погруженный в мысли, Одолев половину дуги моста)

${ }^{2}$ Когда успокоится город

И смолкнет назойливый гам, Один выхожу я из дому, В двенадцать часов по ночам.
}

Под черным, невидимым небом, По тонкому первому льду, Не встретив нигде человека, Не помня дороги, иду.

И вижу широкую реку, И темную тень на коне, И то, что забыла Россия, Тогда вспоминается мне

Но спит непробудно столица Не светит на небе луна. Не бьют барабаны. Из гроба Никто не встает. Тишина.

Лишь с воем летя от залива И будто колебля гранит, Сухой и порывистый ветер Мне ноги снежком порошит [Ковчег, 1991, с. 32-33]. 
рабочем классе: «О, бедные российские воспеватели горна и молота! Они славословят царевококшайскую комячейку, которая в сотрудничестве с комсомолом, укомом и исполкомом в каких-нибудь три воскресника коллективно сконструировала две пары клещей и вычистила полфунта ржавых гвоздей!» (44). Верфь Бельфаста может служить истинным источником поэзии, косвенно отмечает Ходасевич, в отличие от процесса, происходящего в России.

Стиль прозы Ходасевича вообще нельзя назвать эмоциональным или лирическим, он принципиально суховат, сдержан, местами саркастичен и почти холоден. Но ассоциации, создающие многослойность текста, превращающие линейное повествование в объемное и сложное, позволяют увидеть поэтические переплетения и изгибы, которые открывают катастрофичность сознания Ходасевича и скрытый отказ от творчества.

\section{Литература}

Бодлер Ш. Стихотворения. Харьков, 2001.

Бочаров С.Г. Филологические сюжеты. М., 2007.

Данте А. Божественная комедия. М., 1992.

Ковчег: Поэзия первой эмиграции. М., 1991.

Ходасевич В.Ф. Собр. соч.: В 4-х тт. М., 1997. Т. 3.

Baudelaire Charles. Les fleurs du mal. Paris, без года изд.

Dante Alighieri. La divina commedia //

http://www.divinecomedy.org/divine_comedy.html 